\title{
DETERMINING SPECIES EXPANSION AND EXTINCTION POSSIBILITIES USING PROBABILISTIC AND GRAPHICAL MODELS
}

\author{
RAJESH CHATURVEDI, P. RAMA CHANDRA PRASAD
}

Lab for Spatial Informatics, International Institute of Information Technology, Gachibowli, Hyderabad - 500032, India; e-mail: rajesh2990@gmail.com,rcprasad@iiit.ac.in

\begin{abstract}
Chaturvedi R., Prasad R.Ch.: Determining species expansion and extinction possibilities using probabilistic and graphical models. Ekológia (Bratislava), Vol. 34, No. 2, p. 111-120, 2015.

Survival of plant species is governed by a number of functions. The participation of each function in species survival and the impact of the contrary behaviour of the species vary from function to function. The probability of extinction of species varies in all such scenarios and has to be calculated separately. Secondly, species follow different patterns of dispersal and localisation at different stages of occupancy state of the site, therefore, the scenarios of competition for resources with climatic shifts leading to deterioration and loss of biodiversity resulting in extinction needs to be studied. Furthermore, most possible deviations of species from climax community states needs to be calculated before species become extinct due to sudden environmental disruption. Globally, various types of anthropogenic disturbances threaten the diversity of biological systems. The impact of these anthropogenic activities needs to be analysed to identify extinction patterns with respect to these activities. All the analyses mentioned above have been tried to be achieved through probabilistic or graphical models in this study.
\end{abstract}

Key words: biodiversity, disturbances, climate change, endangered, risks, ecological models.

\section{Introduction}

Globally, most of the species (both flora and fauna) are under serious threat from direct and indirect human activities; while direct activities such as deforestation lead to species habitat fragmentation and loss (Miller, Tangley, 1991; Groom, Schumaker, 1993), and changes inclimatic conditions coupled with gas emissions (Matthews et al., 2009; Davis et al., 2010). The synergistic impact of these human-driven activities questions the survivability of organisms in the morphed climatic environments (McCarty et al., 2009). At one level, fragmented habitats increase intra- and interspecies competitions, thus, resulting in decline of populations of species (Hobbs, Yates, 2003), leading to grouping them under rare and threatened category (IUCN, 2001). At another level, the amplified global temperatures in parallel with low precipitation rates not only create unsuitable external habitat conditions, but also impose internal changes in biological clock and physiological processes of the organisms, in addition to their life-history traits (Reynolds et al., 2005; Price, Gittleman, 2007; Bradshaw, Holzapfel, 2010). This kind of changed scenario, both externally and internally, brings incompatibility in the organism to cope with fluctuating climatic conditions, 
finally making the species vulnerable and forcing it into the process of extinction (Wilcox, Murphy, 1985).

The process of species extinction accelerated with rapid human activities and, in the current scenario, many species are in the queue towards extinction (Gilpin, Soule, 1986). Although we are losing our uncounted valuable biodiversity, in a sense, we still do not have an exact idea of how many species are surviving globally, and we are losing them faster than we are able to count the wealth we hold (De Vos et al., 2015). A species may enter the process of extinction under the influence of a single factor or accumulated effect of multiple factors. The rate at which species are subjected to extinction processes may also vary, that is, some at faster rates and some in sequenced slow processes depending on their genetic build-up, ecological tolerance and amplitude (Purvis et al., 2005; Reynolds, 2003; Reynolds et al., 2005). Overall, there is a need to understand the contributing factors that bring about this varied extinction risk among the species and use those factors to model the species extinction rates and processes.

Estimations of IUCN (2009) clearly indicate the worsening scenario of anthropogenic activities on the status of species survivability that need to be addressed under high priority. As per IUCN (2009), about 17,291 species out of 47,677 so far assessed are threatened with extinction indicating loss of almost $36 \%$, of the total estimations, which is a very large number. Of the world's 5490 mammals, 79 are extinct or extinct in the wild, with 188 critically endangered, 449 endangered and 505 vulnerable (IUCN, 2009). The disappearance of mammals at such a fast rate is posing threats to none other than humans (Laurance, 1991). Phylogenetic comparative analysis of species extinctions with reference to mammals, using the global approach model, described geographical range, human population density and latitude as important predictors of species extinction risk (Cardillo et al., 2008).

The research on amphibians of Madagascar by Andreone et al. (2005) categorised all the species according to IUCN list as threatened, critically endangered and vulnerable. The study identified the drivers or predictors for the near extinction of species as over-collection of species for the pet trade on the one hand and low ecological amplitude and continuous habitat loss processes on the other hand as factors most influencing the extinction risks. Similarly, other groups of fauna species are also at equal risk of extinction due to various human-driven destructive factors, for example, Avian species (Szabo et al., 2012), Reptiles (Böhm et al., 2013), etc., including other invertebrate groups that are more sensitive to environmental changes and quantifying their extinction rates is quite challenging and difficult. Compared to animals, plants that are major primary productive sources are much more vulnerable to the extinction risks, questioning the ecological balance (Davies et al., 2011; Fordham et al., 2012).

Keeping in view the high pace at which species are subjected to the processes of extinction, application of conservation measures is utmost needed in the scenario of such crisis (Mace, Baillie, 2007; Cardillo et al., 2006). Since extinction is hidden underlying process of greater impact, utility of species extinction prediction or forecasting models serve as better tools in understanding and estimating the extinction risks faced by species using diverse factors (Sodhi et al., 2009).

Predicting species extinction is one of the most important and challenging areas of conservation biology (Ladle, 2009). Different methods were used by the researchers to predict the extinction process, such as extrapolation (Solow, 2005) and metapopulation models (Bulman et al., 2007), species area and distribution models (Williams et al., 2009; Hubbell et al., 2008). A review 
of all these methods was provided by Ladle (2009) where he states that the probability of extinction estimations by different methods has major limitations, irrespective of their predictions whether in ecological theory or expertise decision.

In the current research, we have tried to discuss the process of species extinction using different models and graphs with different contributing factors. The probabilistic model explained in this study tries to estimate extinction based on governing and limiting factors. The species model developed for a site in Europe, based on historical presence and absence record of species distribution (Doxford, Freckleton, 2012), has been further used in the current research to explain the model process through graphs and identify the nature of selected site.

In certain conditions, species loss and extinction occur due to sudden, unexpected natural catastrophes, such as collision of a large asteroid mass with the earth's surface or volcanic burst or human-induced large scale deforestation activities (Collinge, 1996; Sodhi et al., 2009). These events are considered as drivers of extinction and sinusoids and gaussian curves are applied to understand the sudden destruction phenomena along with growth and expansion of biodiversity.

Thus, the study looks forward to analysing multiple parameters leading to extinction and develop models to predict stages with respect to their extent and influence on the surrounding environment. As a first step, we propose a model to predict probability of extinction of species and thus functional groups as a whole based on models prepared for biological diversity. In contrast, the probability models developed earlier were based on probability of local extinction of species that estimates the loss of essential ecosystem functions (Nijs, Impens, 2000). Furthermore, we generate scenarios depicting extinction based on the colonisation patterns of communities. Finally, applications of gaussian curves and sinusoids are shown with the impacts of human settlements on biodiversity that are being discussed with the help of graph. The population dynamics in plants are known to operate over a long-time scale and are prone to lags in response to environmental changes (Brook et al., 2009); this fact is considered with utmost care while developing the models. All analyses and results are based on either hypothesis or historical data.

\section{Material and methods}

\section{Probabilistic model development}

A single species in an ecosystem is governed by a large number of functions. This model assumes that the species support functions (climate, soil, etc.) in the same way that these functions support the species to flourish. A combination of these functions at a particular location supports species with almost common requirements. Thus, species aided by a similar combination of functions can be called functionally analogous and form a functional group, a group of species requiring 10 inches of annual rainfall and temperature varying between 20 and $25^{\circ} \mathrm{C}$ throughout the year. The probability of a species becoming extinct depends on a multitude of factors with different contributing ratio. For convenience, we assume each factor contributes equally in the process. If $\mathrm{N}$ is the number of factors that aid a single species $\mathrm{S}, \mathrm{P}$ being the probability of the factor behaving contrary, with respect to conditions suitable for species survival, I being the function (words factor and function would be used interchangeably) indicator ( 1 if the species does not get extinct, 0 if species gets extinct with $\mathrm{I}=0$ only if $\mathrm{N}=0$ ), we may state that probability of $\mathrm{I}=0$ equals $\mathrm{P}^{\mathrm{N}}$. (Probability that all $\mathrm{N}$ factors those support $\mathrm{S}$ behaves contrarily). Thus, the probability that $\mathrm{S}$ is not extinct $(\mathrm{I}=1)$ is:

$\mathbf{P}_{\mathrm{e}}=\mathbf{1}-\mathbf{P}^{\mathrm{N}}$,

The range of values of $\mathrm{P}_{\mathrm{e}}$ lies in the range of $0-1$. It is essential for equation 1 that behavioural properties of all functions are similar and one does not affect the other in any form. Figure 1 show the approximate number of functions needed to obtain a given $\mathrm{P}_{\mathrm{e}}$ expressed as a function of $\mathrm{P}$. As part of the extension of these probabilistic values, few results have been drawn in results and conclusion section further in this study. 


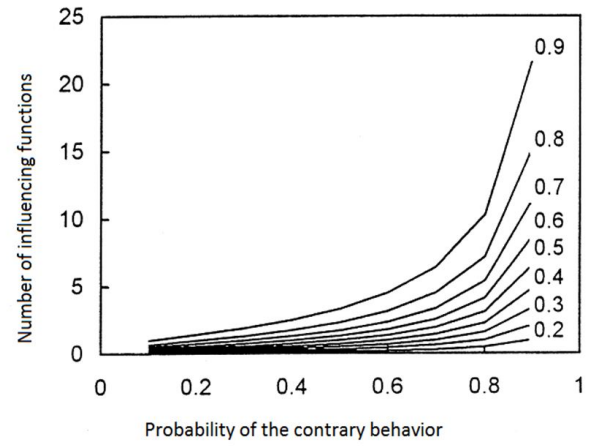

Fig. 1. Variation of probability of contrary behaviour with no. of influencing functions.
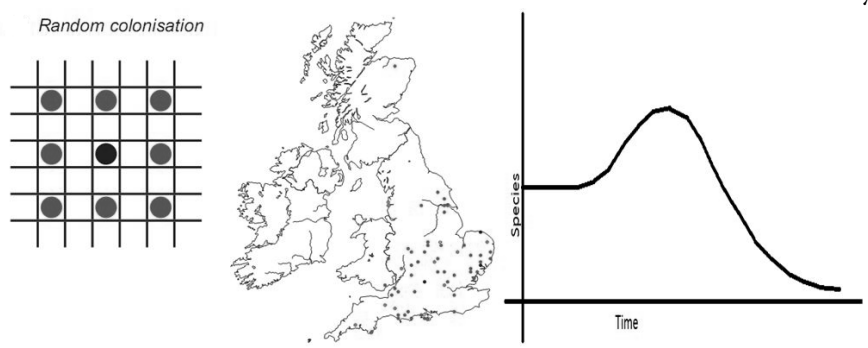

Fig. 2. Random colonisation with developed predictive graph.
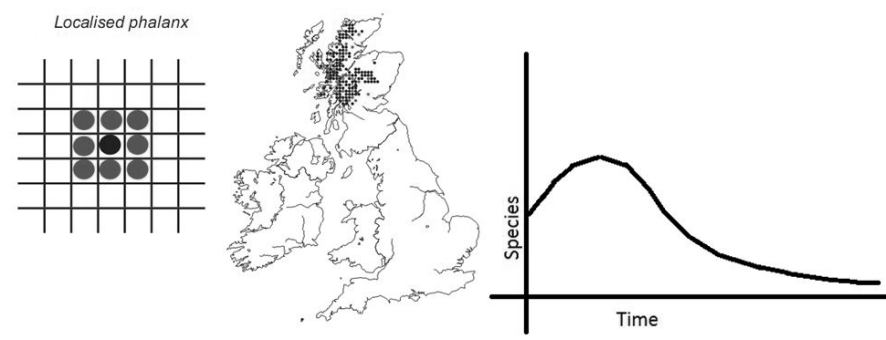

Fig. 3. Localised phalanx with developed predictive graph.
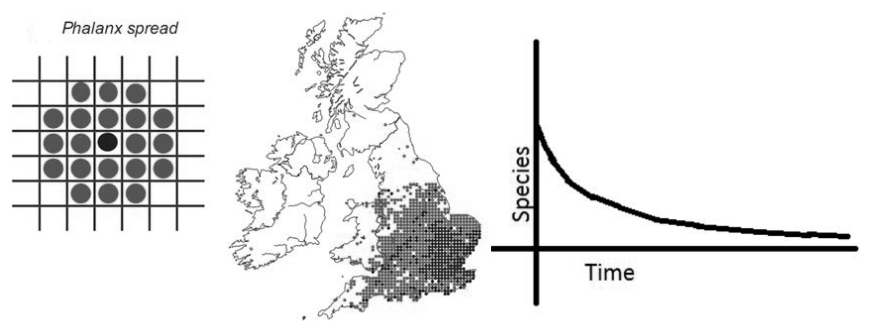

Fig. 4. Phalanx spread with developed predictive graph.
Extinction modeling of species based on models of distribution change and climatic shifts

Three simple mechanisms of distribution change are known, which are translated into extinction patterns based on the colonisation patterns they follow (Doxford, Freckleton, 2012).

The first of these models explains long-range colonisation leading to expansion. For a site to become occupied, sufficient long-range dispersal and suitable habitat to be present randomly are both governing factors. This may be assumed to happen in preliminary stages of succession process, where resources are readily available at all locations and there is hardly any competition for the species to survive. This is termed as a random colonisation model and characterised by chance colonisation of favourite sites beyond immediately neighbouring sites. These types of sites do not show extinction patterns for a while under constant environmental conditions until resource competition does not start and climate keeps on shifting at a slow pace.

The second model states that colonisation takes place in an aggregated manner. Species tend to occupy vacant places in the immediate neighbourhood of currently populated ones. This is called as a localised phalanx model. This is stated to happen in two cases where dispersal is highly restricted or large numbers of supporting sites are created near the occupied ones. This colonisation type attains a state of maximum species distribution, and further competition gives rise to extinction along with climatic shifts against the favour of localised species.

The third model defines the spread process as spatially continuous; it is termed as a phalanx-spread model. Species advance to new suitable habitats. Degradation of habitat from large contiguous areas may lead to large extinction probabilities and change in climatic conditions that is totally against species survival in the mean time. This colonisation type is assumed to be at its peak and large competi- 
tion gives rise to extinction of species and biodiversity deterioration.

Figures 2, 3 and 4 depict random colonisation, localised phalanx and phalanx spread in Great Britain (Doxford, Freckleton, 2012) and graphs developed corresponding to each of them are displayed adjacent to them.

Gaussian and sinusoids in ecological functioning and extinction for natural phenomena

All species follow gaussian curve in the sequence of events starting with succession to extinction with maxima of gaussian curves representing the peak or climax community. The graph is assumed to be a gaussian because the time gap between a positive and negative sinusoid (Fig. 5) is hundreds of years, which suggests that graph necessarily is a form of gaussian curve.

These gaussian curves are governed by sinusoids. The functions governing species distribution and survival form parallel gaussian sinusoids with respect to their growth and depreciation. The crests in a sinusoid represent positive behaviour of functions that support species and similarly, troughs represent negative/contrary behaviour of the function. Species growth and depreciation occur in correspondence with these crests and troughs, which act as delimiters, that is, climax community is reached when crest appears and destabilisation is maximum at troughs. Any disruption/breakage in sinusoid at any point represents the possibility of natural hazard that gives rise to calamity in terms of large species loss at once.

Human settlements and species extinction

The growing numbers of human settlements result in reduction of species (Luck, 2007). In the logistic growth model of human population, we choose lag phase as the basis of studies, it has been assumed that the lag phase approximately follows a parabolic equation. The loss of species due to anthropogenic activities is also assumed to follow parabolic equation.

$$
\mathbf{Y}=\mathbf{a T}^{2} \text { [For human settlements], }
$$

where 'a' is positive constant and ' $\mathrm{T}$ ' is time.

$$
\mathbf{Y}^{\prime}=-\mathbf{b T}^{\prime 2}+\mathrm{S} \text { [For Species], }
$$

where ' $b$ ' is positive constant and ' $S$ ' is the initial number of species. Thus, the graphical parabolic model relating human settlements with decreasing number of species and their extinction is displayed in Figure 6.

\section{Results and discussion}

\section{The concept of dominating functions}

Earlier, we had assumed that all functions contribute equally in species survival and probabilities of contrary behaviour of all of those were assumed to be similar and independent; however, it is not a true assumption. All of these functions vary in contribution towards spe- 
cies survival, which we represent by $\mathrm{W}_{\mathrm{i}}$ for $\mathrm{i}^{\text {th }}$ function. Similarly, the probability of contrary behaviour of the $\mathrm{i}^{\text {th }}$ function is given by $\mathrm{P}_{\mathrm{i}}$ Then, probability of $\mathrm{S}$ being extinct is given by:

$$
\bigcup_{i=1}^{N} \text { WiPi, }
$$

The species gets extinct under duress if all factors fail simultaneously, this probability is

$$
\prod_{\mathrm{i}=1}^{\mathrm{N}} \mathrm{Pi} \text {, }
$$

For all cases, $\mathrm{W}_{\mathrm{i}}$ assumes values between 0 and 1 . For a species, there may be a function $\mathrm{F}_{\mathrm{i}}$, with an exceptionally high weight, thus species survival may largely depend on the behaviour of this particular function, which may also be termed as keystone function (Croley, North, 1988). Suppose, $\mathrm{W}_{1} \mathrm{P}_{1}, \mathrm{~W}_{2} \mathrm{P}_{2}$, and $\mathrm{W}_{3} \mathrm{P}_{3}$ are the probabilities of a species getting extinct when functions $\mathrm{F}_{1}, \mathrm{~F}_{2}$, and $\mathrm{F}_{3}$ behave contrary, respectively. The combined probability with all three functions is given by the union of these. Figure 7 represents the Venn diagrams formed by events of different weights of influencing functions; for the case, the numbers of functions are limited to 3.

\section{Extinction of functional group}

The probability of extinction of functional groups composed of $\mathrm{M}$ species in total can thus be calculated. The functional group is said to be extinct when none of the species constituting

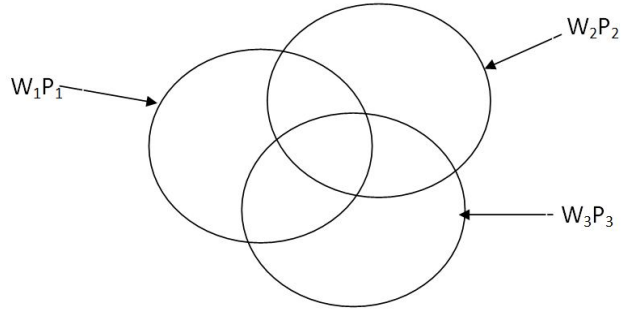

Fig. 7. Venn diagram formed by events of different weights of influencing functions.

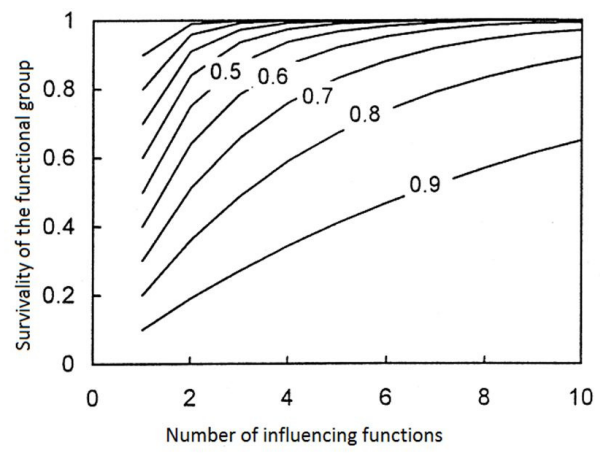

Fig. 8. Variation of number of influencing functions with survival of functional group. the functional group survives in the selected location. This probability of extinction of all species simultaneously is given by:

$$
\prod_{j=1}^{\mathrm{M}} \mathrm{U}_{\mathrm{i}=1}^{\mathrm{N}} \mathrm{WijPi} \text {, }
$$

And, all the species forcibly get extinct when all functions show contrary behaviour. This probability remains the same as that of extinction of single species when all functions show contrary behaviour, that is:

$$
\prod_{i=1}^{N} P i,
$$

In all the calculations, the individual function's behaviour remains independent of the behaviour of all other functions.

Figure 8 represents the relationship between probability of survival of functional group and number of influencing functions. It is a simplified case where all the functions are equal and support species equally. The relationships correspond to different extinction probabilities of functions. 
Predicting the stage of curve by extinction modelling of species based on models of distribution change and climatic shifts

The area of location being occupied by a species is a true measure of the stage on the curve. It is expected that peak is reached when nearly the whole of the concerned area is occupied, that is, there is hardly any room for species to be adjusted within the limited resource pool. This states that the stage of locating maximum number of species that can be adjusted in a particular location occurs when concerned area is fully occupied. At this juncture, the competition for resources begins and species start getting eliminated one after the other with nudation occurring once all the resources are exhausted. The random colonisation is assumed to take place until nearly $50 \%$ of the area is occupied, it is so because, by this stage, there is the probability of a single new habitat against every existing habitat and competition has not started yet. The different stages are clearly labelled in Figure 9.

The graphical representation in Figure 9 can be validated by the following two methods:

Simulated redistribution of suitable climate space for stiff sedge under future climate scenarios in Great Britain and Ireland is shown in Figure 10. Suitable climate space is expected to be lost, with a general migration northwards as climate changes (Pearson, Dawson, 2003; Hulme, Jenkins, 1998).

Also, it is known that extinctions arising from area reductions apply independent of habitat destruction or climate instability. The model suitably fits the equation $S=\mathrm{cA}^{\mathrm{z}}$, where $S$ represents number of species, A represents an area, $c$ and $z$ are constants (Rosenzweig, 1995). Species that become extinct or threatened are adequately calculated by this relation and habitat destruction significantly reduces the area available to them (Brooks et al., 1997, 1999). However, this has been stated in terms of extinction of bird species and could rather be confirmed as the case of mutual interdependency and extinction.

Gaussian and sinusoids in ecological functioning, extinction for natural phenomena, human settlements and species extinction described above are very long processes extending to thousands of years. Hence, the nature of graphs is assumed to be smooth in the model developed. However, considering a lesser number of years, the graph is highly probable to have distortions at more than one place.

\section{Conclusion}

There are knowledge-driven models that use rules to identify relationships between dependent and independent variables in the environment (Skidmore, 2002). Rules in this study have been generated from opinion and induction and deduction approaches.

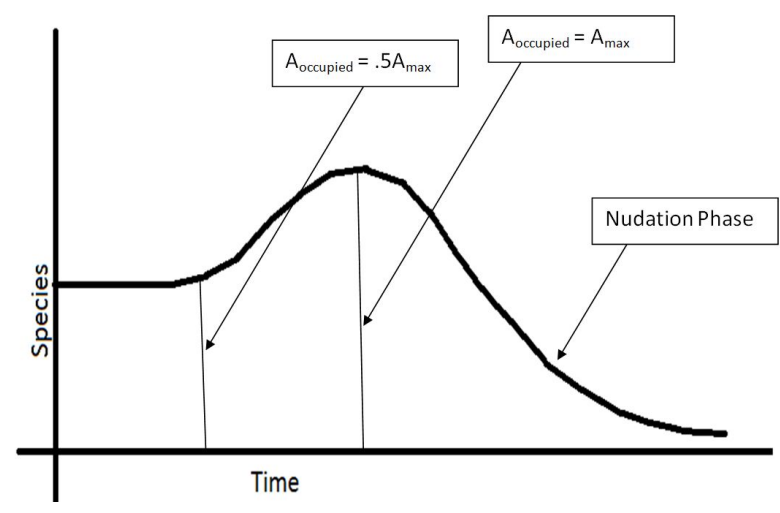

Fig. 9. Predicting stage on the curve. 


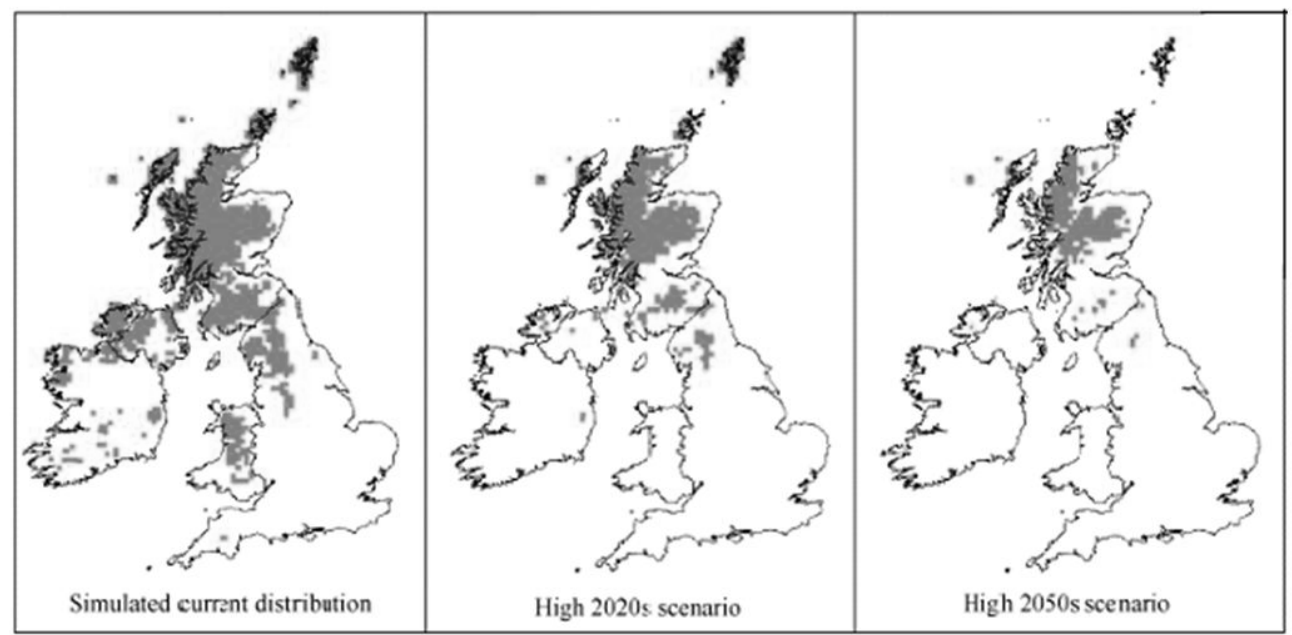

Fig. 10. Proof of model through earlier referenced research work - simulated redistribution of suitable climate space for stiff sedge under future climate scenarios in Great Britain and Ireland.

Formal logic is used to infer conclusions from facts contained within the knowledge base. The models can thus be summarised by the flow:

\section{Given $\rightarrow \mathrm{E}$ (antecedent evidence) $\rightarrow$ then $\rightarrow \mathrm{H}$ (consequent hypothesis)}

The study thus discusses three models that determine probabilities of extinction of species and functional groups as a whole when individual probabilities of functions are known. Further, predicted extinction curves of species have been modelled with respect to time, depending on localisation patterns of species. The points on these curves can be identified by another model that is concerned with the area of a location acquired by species. Further, sinusoids and gaussian curves are used to model the ecological functioning and disruption to formulate the hypothesis of extinction at rupture points of these curves. Finally, extinction has been modelled with respect to growing human settlements in the form of parabolic functions.

To each probabilistic and graphical model suggested in this study, there are specific premises on which they have been proposed. The models developed earlier proving the extinction processes due to abrupt climate changes have been developed already with evidences (Croley, North, 1988). Corresponding to the type of climate changes and their extent, it is also possible to predict their impact on changes in distribution or extinction risks (Pearson, Dawson, 2003). Similarly, there are simulation models for transient effects of climate change on forest landscapes (Colin et al., 1992). Combining all these models along with those stated in this study helps in assessing the extinction easily. In a similar way, the relation between the human activities and loss of biodiversity described in this study can be accompanied by population densities and biodiversity studies to predict the closeness to extinction of species in a particular area (Luck, 2007). 
The future work corresponding to each of these models would be the development of models for conservation of species and thus biodiversity corresponding to each scenario of mass extinction or slow procedural extinction.

\section{Acknowledgements}

We acknowledge the use of maps presented by Doxford and Freckleton in Journal of Ecology (2011) as a proof for our proposed research.

\section{References}

Andreone, F., Cadle, J.E., Cox, N., Glaw, F., Nussbaum, R.A., Raxworthy, C.J., Stuart, S.N., Vallan, D. \& Vences M. (2005). Species review of amphibian extinction risks in Madagascar: conclusions from the global amphibian assessment. Conserv. Biol., 19(6), 1790-1802. DOI: 10.1111/j.1523-1739.2005.00249.x.

Böhm, M., Collen, B., Baillie, J.E., Bowles, P., Chanson, J., Cox, N. et al. (2013). The conservation status of the world's reptiles. Biol. Conserv., 157, 372-385. DOI :10.1016/j.biocon.2012.07.015.

Bradshaw, W.E., Holzapfel C.M. (2010). Light, time, and the physiology of biotic response to rapid climate change in animals. Annu. Rev. Physiol., 72, 147-166. DOI: 10.1146/annurev-physiol-021909-135837.

Brook, B.W., Akcakaya, H.R., Keith, D.A., Mace, G., Pearson, R.G. \& Araujo M.B. (2009). Integrating bioclimate with population models to improve forecasts of species extinctions under climate change. Biology Letters, 5(6), 723-725. DOI: $10.1098 / \mathrm{rsbl} .2009 .0480$.

Brooks, T.M., Pimm, S.L. \& Collar N.J. (1997). Deforestation predicts the number of threatened birds in insular Southeast Asia. Conserv. Biol., 11(2), 382-394. DOI: 10.1046/j.1523-1739.1997.95493.x.

Brooks, T.M., Pimm, S.L. \& Oyugi J.O. (1999). Time lag between deforestation and bird extinction in tropical forest fragments. Conserv. Biol., 13(5), 1140-1150. DOI: 10.1046/j.1523-1739.1999.98341.x.

Bulman, C.R., Wilson, R.J., Holt, A.R., Bravo, L.G., Early, R.I., Warren, M.S. \& Thomas C.D. (2007). Minimum viable metapopulation size, extinction debt, and the conservation of a declining species. Ecol. Appl., 17, 1460-1473. DOI: 10.1890/06-1032.1.

Cardillo, M., Mace, G., Gittleman, J.L. \& Purvis A. (2006). Latent extinction risk and the future battlegrounds of mammal conservation. Proc. Natl. Acad. Sci. USA, 103, 4157-4161. DOI: 10.1073/pnas.0510541103.

Cardillo, M., Mace, G.M., Gittleman, J.L., Jones, K.E., Bielby, J. \& Purvis A. (2008). The predictability of extinction: biological and external correlates of decline in mammals. Proc. R. Soc. Biol. Sci. Ser. B, 275(1641), 1441-1448. DOI: 10.1098/ rspb.2008.0179.

Colin, I., Sykes, M.T. \& Cramer W. (1992). A simulation model for transient effects of climate change on forest landscapes. Ecol. Model., 65, 51-70. DOI: 10.1016/0304-3800(93)90126-D.

Collinge, S.K. (1996). Ecological consequences of habitat fragmentation: implications for landscape architecture and planning. Landsc. Urban Plann., 36, 59-77. DOI: 10.1016/S0169-2046(96)00341-6.

Croley, T.J. \& North G.R. (1988). Abrupt climate changes and extinction in earth history. Science, 240(4855), 996-1002. DOI: $10.1126 /$ science.240.4855.996.

Davies, T.J., Smith, G.F., Bellstedt, D.U., Boatwright, J.S. \& Bytebier B. et al. (2011). Extinction risk and diversification are linked in a plant biodiversity hotspot. PLOS Biology, 9(5), e1000620. DOI: 10.1371/journal.pbio.1000620.

Davis, S.J., Caldeira, K. \& Matthews H.D. (2010). Future $\mathrm{CO}_{2}$ emissions and climate change from existing energy infrastructure. Science, 329(5997), 1330-1333. DOI: 10.1126/science.1188566.

De Vos, J.M., Joppa, L.N., Gittleman, J.L., Stephens, P.R. \& Pimm S.L. (2015). Estimating the normal background rate of species extinction. Conserv. Biol., 29(2), 452-462. DOI: 10.1111/cobi.12380.

Doxford, S.W. \& Freckleton R.P. (2012). Changes in the large-scale distribution of plants extinction, colonization and the effects of climate. J. Ecol., 100, 519-529. DOI: 10.1111/j.1365-2745.2011.01902.x.

Fordham, D.A., Resit Akçakaya, H., Araújo, M.B., Elith, J., Keith, D.A., Pearson, R., Auld, T.D., Mellin, C., Morgan, J.W., Regan, T.J., Tozer, M., Watts, M.J., White, M., Wintle, B.A., Yates, C. \& Brook B.W. (2012). Plant extinction risk under climate change: are forecast range shifts alone a good indicator of species vulnerability to global warming? Global Change Biology, 18, 1357-1371. DOI: 10.1111/j.1365-2486.2011.02614.

Gilpin, M.E. \& Soule M.E. (1986). Minimum viable populations: processes of species extinction. In M.E. Soule (Ed.), Conservation biology (pp. 19-34). Sunderland: Sinauer Associates. 
Groom, M.J. \& Schumaker N. (1993). Evaluating landscape change: patterns of worldwide deforestation and local fragmentation. In P.M. Kareiva, J.G. Kingsolver \& R.B. Huey (Eds.), Biotic interactions and global change (pp. 24-44). Sunderland: Sinauer Associates.

Hobbs, R.J. \& Yates C.J. (2003). Impacts of ecosystem fragmentation on planpopulations: generalising the idiosyncratic. Aust. J. Bot., 51 , 471-488. DOI: 10.1071/BT03037.

Hubbell, S.P., He, F., Condit, R., Borda-de-Água, L., Kellneri, J. \& ter Steege H. (2008). How many tree species are there in the Amazon and how many of them will go extinct? Proc. Natl. Acad. Sci. USA, 105(Suppl. 1), 11498-11504. DOI: 10.1073/pnas.0801915105.

Hulme, M. \& Jenkins G.J. (1998). Climate change scenarios for the UK. UKCIP Technical Report No. 1. Norwich: Climatic Research Unit.

IUCN (2001). Red List of Threatened Species. IUCN Red List Categories and Criteria version 3.1. Gland: IUCN Species Survival Commission.

IUCN (2009). IUCN Red List of Threatened Species, v2009. iucnredlist.org

Ladle, R.J. (2009). Forecasting extinctions: uncertainties and limitations. Diversity, 1(2), 133-150. DOI:10.3390/d1020133.

Laurance, W.F. (1991). Ecological correlates of extinction proneness in Australian tropical rain forest mammals. Conserv. Biol., 5, 79-89. DOI: 10.1111/j.1523-1739.1991.tb00390.x.

Luck, G.W. (2007). A review of the relationships between human population density and biodiversity. Biol. Rev., 82(4), 607-645. DOI: 10.1111/j.1469-185X.2007.00028.x.

Mace, G.M. \& Baillie J.E.M. (2007) The 2010 biodiversity indicators: challenges for science and policy. Conserv. Biol., 21, 1406-1413. DOI: 10.1111/j.1523-1739.2007.00830.x.

Matthews, H.D., Gillett, N.P., Stott, P.A. \& Zickfeld K. (2009). The proportionality of global warming to cumulative carbon emissions. Nature, 459, 829-833. DOI: 10.1038/nature08047.

McCarty, J.P, Wolfenbarger, L. LaReesa, \& Wilson J.A. (2009). Biological impacts of climate change. Chichester: John Wiley \& Sons Ltd. DOI: 10.1002/9780470015902.a0020480.

Miller, K. \& Tangley L. (1991). Trees of life: saving tropical forests and their biological wealth. Boston: Beacon Press.

Nijs I. \& Impens I. (2000). Biological diversity and probability of local extinction of ecosystems. Funct. Ecol., 14, 46-54. DOI: 10.1046/j.1365-2435.2000.00394.x.

Pearson, R.G., Dawson T.P. (2003). Predicting the impacts of climate change on the distribution of species: are bioclimate envelope models useful? Glob. Ecol. Biogeogr., 12, 361-371. DOI: 10.1046/j.1466-822X.2003.00042.x.

Price, S.A. \& Gittleman J.L. (2007). Hunting to extinction: biology and regional economy influence extinction risk and the impact of hunting in artiodactyls. Proc. R. Soc. Lond. B, 274(1620), 1845-1851. DOI: 10.1098/rspb.2007.0505.

Purvis, A., Cardillo, M., Grenyer, R. \& Collen B. (2005). Correlates of extinction risk: phylogeny, biology, threat and scale. In A. Purvis, J.L. Gittleman \& T. Brooks (Eds.), Phylogeny and conservation (pp. 295-316). Cambridge: Cambridge University Press.

Reynolds, J.D. (2003). Life histories and extinction risk. In T.M. Blackburn \& K.J. Gaston (Eds.), Macroecology: concepts and consequences (pp. 195-217). Oxford: Blackwell.

Reynolds, J.D., Dulvy, N.K., Goodwin, N.B. \& Hutchings J.A. (2005). Biology of extinction risk in marine fishes. Proc. R. Soc. Lond. B, 272(1579), 2337-2344. DOI: 10.1098/rspb.2005.3281.

Rosenzweig, M.L. (1995). Species diversity in space and time. Cambridge: Cambridge University Press.

Skidmore, A. (Ed.). (2004). Environmental modelling with GIS and remote sensing. CRC Press.

Sodhi, N.S., Brook, B.W. \& Bradshaw C.J.A. (2009). Causes and consequences of species extinctions. In S.A.Levin (Ed.), Princeton guide to ecology (pp. 514-520). Princeton: Princeton University Press.

Solow, A.J. (2005). Inferring extinction from a sighting record. Math. Biosci., 195, 47-55. DOI: 10.1016/j.mbs.2005.02.001.

Szabo, J.K., Khwaja, N., Garnett, S.T. \& Butchart S.H. (2012). Global patterns and drivers of avian extinctions at the species and subspecies level. PLOS One, 7(10), e47080. DOI: 10.1371/journal.pone.0047080.

Wilcox, B.A. \& Murphy D.D. (1985). Conservation strategy: the effects of fragmentation on extinction. Am. Nat., 125: 879-887. DOI: 10.1111/j.1365-2699.2009.02110.x.

Williams, M.R., Lamont, B.B. \& Henstridge J.D. (2009). Species-area functions revisited. J. Biogeogr., 36, 1994-2004. http:// www.jstor.org/stable/2461453. 